\title{
GIM-TEC adaptive ionospheric weather assessment and forecast system.
}

\author{
T.L. Gulyaeva ${ }^{1}$, F. Arikan ${ }^{2}$, M. Hernandez-Pajares ${ }^{3}$, I. Stanislawska ${ }^{4}$
}

${ }^{1}$ IZMIRAN, Kaluzskoe Sh. 4, Troitsk, Moscow 142190, Russia gulyaeva@izmiran.ru

${ }^{2}$ Department of EEE, Hacettepe University, Beytepe, Ankara 06800, Turkey arikan@ hacettepe.edu.tr

${ }^{3}$ Universitat Politecnica de Catalunya (UPC) Barcelona, Spain manuel@ma4.upc.edu

${ }^{4}$ Space Research Center, PAS, Warsaw, Poland stanis@cbk.waw.pl

\section{Abstract}

The Ionospheric Weather Assessment and Forecast (IWAF) system is a computer software package designed to assess and predict the world-wide representation of 3-D electron density profiles from the Global Ionospheric Maps of Total Electron Content (GIM-TEC). The unique system products include daily-hourly numerical global maps of the F2 layer critical frequency (foF2) and the peak height (hmF2) generated with the International Reference Ionosphere extended to the plasmasphere, IRI-Plas, upgraded importing the daily-hourly GIM-TEC as a new model driving parameter. Since GIM-TEC maps are provided with one- or two-days latency, the global maps forecast for one day and two days ahead is envisaged using the harmonic analysis applied to the temporal changes of TEC, foF2 and hmF2 at 5112 grid points of a map encapsulated in IONEX format $\left(-87.5^{\circ}: 2.5^{\circ}: 87.5^{\circ} \mathrm{N}\right.$ in latitude, $180^{\circ}: 5^{\circ}: 180^{\circ} \mathrm{E}$ in longitude). The system provides online the ionospheric disturbance warnings in the global W-index map establishing categories of the ionospheric weather from the quiet state $(\mathrm{W}= \pm 1)$ to intense storm $(\mathrm{W}= \pm 4)$ according to the thresholds sets for instant TEC perturbations regarding quiet reference median for the preceding 7 days. The accuracy of IWAF system predictions of TEC, foF2 and hmF2 maps is superior than the standard persistence model with prediction equal to the most recent 'true' map. The paper presents outcome of the new service expressed by the global ionospheric 
foF2, hmF2 and W-index maps demonstrating process of origin and propagation of positive and negative ionosphere disturbances in space and time and their forecast under different scenarios.

Key words: Ionospheric weather, Global ionospheric map, Total electron content, Crirical frequency, Peak height, IRI-Plas

\section{Introduction.}

The requirement for near real-time products based upon current ionospheric specification has led to an increased importance of the real-time ionospheric models. These products are required for reliable HF communications along short-, medium- and long-range paths, satellite communication, navigation, guidance, control and positioning systems. With Global Positioning System, GPS, (acronyms are listed in Table 1) providing instantaneous time delay, or equivalently, the total electron content (TEC), the GPS-TEC values are estimated for the Earth based reference stations, and further processed by the International GNSS Service (IGS) ionospheric working group (Iono-WG) to produce the Global Ionospheric Maps (GIM), available online since 1998 (Manucci et al., 1998; Dow et al., 2009; Hernandez-Pajares et al., 2009). Among a variety of techniques applied to probe the ionosphere, the GPS monitoring and the vertical sounding with ground-based and satellite-based ionosondes are the most recognized sources of information on the ionosphere. Though the ionosonde network of sounding stations is operating for more than 70 years, its products are not used for the real-time global ionospheric mapping so far due to data sparsity in time and position over the globe. Instead, the efforts are focused on regional mapping of the ionosphere parameters for the areas of the denser set of the ionosonde observatories (Zolesi and Cander, 2000). Also the particular interest has centered on longterm global maps for radio-circuit design, service planning and frequency-band selection (Bradley et al., 2009).

Up to now, the reference global maps of monthly median of the F2 layer peak parameters, e.g. ITU-R (CCIR, 1976; 1991) maps of the critical frequency foF2 and the radio wave propagation factor 
M3000F2 (Jones and Gallett, 1962) and URSI foF2 maps (Rush et al., 1989) are available, in particular, in the International Reference Ionosphere (IRI) system (Bilitza, 2001). Each map allows for a dependence on position, time, and solar epoch as given by spherical harmonic functions of geographic latitude, geographic longitude and Universal Time (UT) for selected level of solar activity. The associated numerical coefficients are chosen to match a data set of measurements from the world network of vertical-incidence ionosondes for the years of 1954, 1955 and 1964 for solar minimum and 1956-1958 for solar maximum.

The temporal and spatial sparsity of data (e.g. the measurements of the ground-based ionosondes located mainly on the land but rare over the oceans as shown in Figure 6) that have been included in the development of IRI model can be compensated either by assimilation of new ionosonde measurements, or by upgrading the IRI model to include situations like space weather storms (AraujoPradere et al., 2002; Gulyaeva, 2012). When the first option is not feasible, it is better to approach the problem with a cost-effective improvement in the IRI model. The International Reference Ionosphere extended to the plasmasphere (IRI-Plas) (Gulyaeva et al., 2011) is the recent version of IRI where the region of interest can include plasmasphere up to the height of 20,200 km (GPS orbit) so that the GPSderived Total Electron Content (GPS-TEC) can be ingested into IRI-Plas for better representation of the temporal variations in the ionosphere and plasmasphere. As it is envisaged by IRI and IRI-Plas algorithms, the model electron density height profile, $\mathrm{Ne}(\mathrm{h})$, is parameterized using a relative layer shape formula depending on vertical coordinate adapting the absolute values to those at the peak: the peak electron density, $\mathrm{NmF}$, proportional to the critical frequency, foF2, and the corresponding peak height, hmF2 (Gulyaeva and Bilitza, 2012). Daily-hourly implementation of plasmasphere part of IRIPlas code requires knowledge and prediction of 3-hrs geomagnetic kp-index. The daily data for the past are provided online by Geomagnetic Data Service at Potsdam, and forecast for the forthcoming hours of the day is produced in IWAF system with technique presented by De Franceschi et al. (2001). The advantage of IRI-Plas code is the span of model electron density profile in the altitude range from the bottom of the ionosphere $(65-80 \mathrm{~km})$ to $20,200 \mathrm{~km}$ (GPS orbit) relevant for automatic 
conversion of the integral TEC into 3-D electron density profile (versus latitude, longitude and height). Going from an integral TEC to a height profile allows a reliable assessment of one key profile parameter, namely, the foF2 critical frequency (or the equivalent peak electron density, NmF2), accompanied by update of the topside scale height in terms of foF2 (Gulyaeva et al., 2011). Using deviation of TEC-adapted foF2 from its quiet reference one can produce the related change of the peak height, hmF2 (Gulyaeva, 2012). When the both ionosphere peak parameters and the topside scale height are specified, the process of TEC conversion to the vertical electron density profile $\mathrm{Ne}(\mathrm{h})$ passing through the ionization peak, is accomplished with the IRI-Plas model. This procedure has been successfully applied in evaluating the global electron content in the spherical segment of the interplanetary space from the Earth's surface to altitude of 20,200 km (GPS orbit) in the the plasmasphere (Gulyaeva and Veselovsky, 2012).

The purpose of the present project is the development of the Ionospheric Weather Assessment and Forecast (IWAF) system using an assimilation of GIM-TEC by IRI-Plas code to make it capable to assess and predict the world-wide representation of 3-D electron density profiles, the daily-hourly global maps of the F2 layer critical frequency, peak height, and the ionospheric weather W-index maps. Since the daily-hourly GIM-TEC are available with a one day or two days latency due to insufficient stock of more recent GPS source information, the global maps forecast product for one day and two days ahead is provided with the harmonic analysis applied to the temporal changes of TEC, foF2 and hmF2 at each grid point of a map encapsulated in IONEX format (Shaer et al., 1998). The harmonic analysis is based on observations for four preceding days similar to foF2 forecasting (Vodjannikov and Gordienko, 2011) as described in Section 3. Adding the forecasting procedure, IWAF system products include daily-hourly results for the current day (with 1-day ahead forecast), and forecast for the next day (2-days ahead forecast). The results of IWAF maps prediction are compared with other GIM-TEC products (Hernandez-Pajares et al., 2009; Garcia-Rigo et al., 2011) and the standard persistence model which assumes that prediction is equal to the most recent 'true' data. Validation of IWAF Forecast Procedure is provided in Section 4. 
An increased knowledge of effects imposed by the ionosphere on operational radio systems

could be earned by the new service providing online estimate of the degree of TEC perturbation at each grid point of the map expressed by the ionospheric $\mathrm{W}$ index. The $\mathrm{W}$ index reveals TEC behavior varying from quiet state $(\mathrm{W}= \pm 1)$ to intense storm $(\mathrm{W}= \pm 4)$ providing a useful proxy index driving the space weather in the ionosphere-plasmasphere environment rather than the geomagnetic indices alone (Gulyaeva and Stanislawska, 2008; 2010). We have applied W indexing to the GIM-TEC products provided by the Universitat Politecnica de Catalunya (UPC) and Jet Propulson Laboratory (JPL) for generating online the hourly W index maps for a period from January 1999 up-to-date. The planetary $\mathrm{Wp}$ index representing span between the greatest positive storm magnitude occurrence $(\mathrm{W}=3$ or 4$)$ and the least negative storm magnitude ( $\mathrm{W}=-3$ or -4$)$ at each latitude weighted by the occurrence of the both signs stormy indices on a map is used for generating the "Catalogue of the planetary ionosphere storms". Although the planetary Wp-storms comprise approximately $10 \%$ of time in a long-term perspective, their impact on the technological devices is increasing, creating a high risk for their mulfunction. An increasing number of space weather storms may cause serious threat to various technological systems due to their increased dependency on satellite and power systems.

Analysis of the $\mathrm{W}$-index variation in space and time provides information on the ionosphere state under the different scenarios. Appendix A introduces the formulae for the $\mathrm{W}$-index derivation from GIM-TEC maps. Results and discussion are given in Section 5, followed by Conclusions in Section 6.

\section{GIM-TEC Data Selection}

The Global Positioning System (GPS) presents a global network of satellites which ensures a global coverage for monitoring the satellite-emitted dual-frequency signals yielding information on the ionospheric parameters along the propagation path. The GPS-derived information on the integrated ionospheric parameters along the trans-ionospheric path of the signals, i.e. the time delay measurements of the satellite-emitted signal is converted into Total Electron Content (TEC), which is the total number of electrons in a cylinder with a cross section of $1 \mathrm{~m}^{2}$ with its axis along a ray path. 
131 The slant TEC is transformed to vertical TEC at the sub-ionospheric piercing point (Smith et al., 2008)

132 from which the global ionospheric maps, GIM-TEC, are generated in a continuous operational way by 133 several Data Analysis Centers since 1998, covering the period more than the entire solar cycle 134 (Manucci et al., 1998; Dow et al., 2009; Hernandez-Pajares et al., 2011). Typically, GIM-TEC is provided with two hour time resolution. The hourly files, JPLR and JPLG, are provided by Jet 136 Propulson Laboratory since December, 2008, and hourly UHRG files are provided by Universitat 137 Politècnica de Catalunya since October, 2010. which are chosen as the source input in IWAF system. 138 The JPLR and JPLG are generated in the denser map grids (-90:2:90 ${ }^{\circ}$ in latitude, $-180: 2: 180^{\circ}$ in 139 longitude), and time specified for 0.5:1.0:23.5 hrs UT so these maps are preprocessed by linear 140 interpolation into standard IONEX format for 0:1:23 hrs UT. The vertical TEC is modeled by JPL in a 141 solar-geomagnetic reference frame using bi-cubic splines on a spherical grid; a Kalman filter is used to 142 solve simultaneously for instrumental biases and VTEC on the grid as stochastic parameters (Manucci 143 et al., 1998). The UHRG is produced by UPC software TOMION (TOmographic Model of the 144 IONosphere) using a Kriging based interpolation scheme (Orus et al, 2005) to get global coverage. 145 Both the input and output IWAF maps are provided in IONEX format collected in a daily set of the 146 hourly maps with $1 \mathrm{~h}$ UT resolution. The IONEX map consists of 5112 grid values binned in $87.5^{\circ} \mathrm{S}$ to $14787.5^{\circ} \mathrm{N}$ in step of $2.5^{\circ}$ in latitude, $180^{\circ} \mathrm{W}$ to $180^{\circ} \mathrm{E}$ in step of $5^{\circ}$ in longitude. If the input data file is 148 missed for a certain day, it is substituted by another GIM-TEC product. When an input IONEX file is 149 available only with $2 \mathrm{~h}$ UT resolution, the linear interpolation in time is applied to bring GIM-TEC for $1501 \mathrm{~h}$ UT resolution.

A recent assessment of the performance of UHRG VTEC global maps corresponding to the last 152 available 170 days (May to October 2012) is provided in Figure 1. It is remarkable to notice that the 153 UHRG performance is typically better than the combined rapid and final IGS VTEC maps, especially 154 during the last 120 days (right after the last software update), with daily standard deviations 155 systematically 0.5 to 1 TECU lower (in a range of 2 to 5 TECU), and relative RMS percentage of 15$15625 \%$, instead of $20-25 \%$ for the combined IGS products. 


\section{The Forecasting Procedure incorporated in IWAF system}

Since the daily-hourly GIM-TEC are available with a one day or two days latency due to insufficient stock of more recent GPS-related information in RINEX format (Hernandez-Pajares et al., 2009), the global maps forecast product in the framework of IWAF system is envisaged for one day and two days ahead. There are different techniques applied for forecasting of the different ionospheric parameters (Rose, 1993; Jakowski et al., 2002; Garcia-Rigo et al., 2011; Gulyaeva, 2012; Blanch and Altadill, 2013; and references therein). In particular, the Disturbance Impact Assessment System (DIAS) is designed by Rose (1993) as an expert system to assess and predict the influence of the solar flares on high-latitude HF radio communications covering rules and warnings on the sudden ionospheric disturbances, polar cap absorption, ionospheric critical frequency storm, auroral zone absorption and auroral sporadic E and auroral E layers appearance. Review of the different techniques of GIM-TEC forecast designed in the frame of the International GNSS Service and the UPC prediction performance are summarized by Garcia-Rigo et al. (2011). Magnetosphere-ionosphere interactions used for forecasting the F2 layer peak parameters are discussed by Blanch and Altadill (2013). Empirical model of storm-time update of the F2 layer peak height hmF2 in terms of the foF2 changes deduced from the topside sounding data base (Gulyaeva, 2012) is employed by IWAF system as mentioned in the Introduction.

The Fourier Series Expansion is applied in the forecasting procedure of IWAF system based on the temporal changes of TEC, foF 2 and $\mathrm{hmF} 2$ at each grid point of a map encapsulated in IONEX format. Historical source GIM-TEC and the output foF2 and hmF2 maps during four latest days (the latest 'true' 96 hourly maps) are used to produce five spherical harmonic coefficients similar to the 179 ionosonde foF2 forecast (Vodyannikov and Gordienko, 2011). The Fourier analysis limited by five harmonics is aimed to represent mainly the general features of map variations based on the data for

181 four preceding days which provides a reasonable compromise between the reliability of results and the low cost of data processing. 
184 Universal Time, UT) is based on synthesis of mean $\bar{x}$ (average of data for the preceding 96 hourly 185 values at the times $t-96, t-95, \ldots, t-1$ for a given grid point) and the sum of 5 harmonic terms of, $t$ :

186

188

189

190

191

192

$$
X=\bar{X}+\sum_{i=1}^{5}\left[A_{i} \sin (2 \pi i t / 24)+B_{i} \cos (2 \pi i t / 24)\right]
$$

Coefficients $A_{i}$ and $B_{i}$ are derived from $N$ source values of $X_{k}$ :

$$
A_{i}=\frac{2}{N} \sum_{k=1}^{96} X_{k} \sin (2 \pi i t / 24)
$$

$$
B_{i}=\frac{2}{N} \sum_{k=1}^{96} X_{k} \cos (2 \pi i t / 24)
$$

The Eqns. (1-2) reproduce the diurnal variation of $X$ parameter one day ahead taking into account the diurnal $(24 \mathrm{~h})$, semi-diurnal $(12 \mathrm{~h}), 8 \mathrm{~h}, 6 \mathrm{~h}$, and $4 \mathrm{~h}$ tidal components. Though the harmonics are given in terms of the universal time, $t$, the period of 24 local hours around the world is fully represented by the global UT map (Maruyama, 2010). Each harmonic based on the relevant maps for four recent days can be treated as a separate object of a particular physical meaning, for example, the first harmonic of the diurnal variation of foF $2, \mathrm{hmF} 2$ and TEC depicts the results of feeding the ionosphere and plasmasphere by the solar ionizing radiation; the second harmonic is related with halfdiurnal variations of the plasma density separated on the Earth by the solar terminator (Somsikov, 2011). The higher order harmonics may be due to the solar wind energy input captured by the magnetosphere (Gulyaeva and Veselovsky, 2012), transformed and dissipated in the polar upper atmosphere (Rose, 1993) that triggers and drives the ionospheric storm effects along the magnetic field lines between the conjugate hemispheres (Gulyaeva et al., 2011, 2012). The harmonic analysis is 
applied for the prediction one day ahead and the first prediction results serve as an input combined with the source GIM-TEC maps for three preceding days in order to forecast an ionospheric map two days in advance.

\section{Validation of IWAF Forecast Procedure}

The validation of the forecasting technique is made comparing one day forecast and two days forecast of TEC maps with 'true' UHRG which is available later on for the particular day. The normalized relative error $\delta \mathrm{X}$ for IWAF forecast is compared with different GIM-TEC maps (both real maps and forecast) available from Iono-WG. The $\delta \mathrm{X}$ error with $\mathrm{X}$ assigned for foF2, hmF2 or TEC value is calculated as

$$
\delta X=\frac{1}{n} \sum_{i=1}^{n} \sqrt{\frac{\left(X_{o b i}-X_{i}\right)^{2}}{\left(X_{o b i}-\bar{X}_{o b}\right)^{2}}}
$$

where $X_{i}$ presents a grid value of the one day (or two days) IWAF forecast, Z1PG, (or Z2PG) or other Iono-WG IONEX maps. The UHRG map provides a reference 'true' value $X_{o b i}$ at a grid point and the global mean $\bar{x}_{o b}$ averaged for the total 5112 grid points of the UHRG map, $n$, which is the total number of $X$ grid values in an IONEX daily collection of maps.

An example of the comparison is plotted in Figure 2 for a quiet day on April 25, 2011 (left panel), and a storm day on September 17, 2011 (right panel). Results for 1 day forecast by IWAF system Z1PG shows minimum $\delta$ TEC error for the quiet day as compared with other GIM-TEC products. This means that a departure of the IWAF prediction of TEC map from the true UHRG map is less than the difference between the different Iono-WG maps for the quiet day. This advantage,

229 however, is not so evident for the sunlit hours of the storm day (right panel) when the IWAF 1-day 230 ahead forecast for the storm day remains more accurate than the 2-days ahead forecast U2PG (Garcia- 
Rigo et al., 2011) and more consistent with the UHRG true data than the mean Iono-WG IGRG map which smoothes the extreme storm signatures during averaging of the few source GIM-TEC maps.

The one day forecast and two days forecast by the IWAF system are compared in Table 2 for the worst case storm day on October 1, 2012, when the extreme ring current index Dst $=-143 \mathrm{nT}$, and the GIM-TEC derived planetary Wp index (Gulyaeva and Stanislawska, 2008; 2010) varies between $\mathrm{Wp}=3.5$ and the peak $\mathrm{Wp}=6.7$ i.u. (index units) during the day (see $\mathrm{Wp}$ and Dst variation in Figure 7). The comparisons in Table 2 are made using the relative error $\delta X$ (Eqn. 3). The total number of the grid values used for the comparison amounts to $n=122,688$ for the 24 daily-hourly set of the maps, for each type of a map (foF2, hmF2, TEC) and two types of forecast products (1-day and 2-days ahead). The IWAF forecast is based on UHRG maps for 27-30 September, 2012, in producing the one day forecast for October 1, and on UHRG maps for 27-29 September, 2012, and also 1-day forecast for September 30, 2012, in producing the 2-days forecast for October, 1. Results are given in Table 2 in terms of local time, hours, compiled and averaged from 0 to $23 \mathrm{~h}$ UT maps. Results presented in Table 2 appear to be very promising. The $\delta \mathrm{X}$ error is less during the night than during the daytime, slightly growing towards noon. The 2-day forecast is slightly less accurate than the 1-day forecast as should be expected. The forecast product maps of foF 2 and hmF2 (being based on IRI-Plas products of the relevant maps) show a better accuracy than the TEC forecast which is compared with the 'true' reference UHRG map for the October, 1.

Figure 3 presents the comparison of the preliminary real-time (RT) UPC TEC maps, URTG, computed with a limited number of 70 to 80 GPS receivers during 17-24 January, 2012, with IWAF 1day predicted TEC maps, Z1PG, against Topex/Jason daily mean TEC. The Topex/Jason altimeter provides the ionospheric TEC measurements over the oceans at altitudes below 1,336 km (Topex/Jason orbit) which do not include the plasmasphere contribution present in GPS-TEC, so an allowance for GPS-TEC exceeding Topex/Jason TEC should be kept in mind when comparing these two data sources (Azpilicueta and Brunini, 2008; Gulyaeva et al., 2009; Lee et al., 2013). The planetary Wp index (Gulyaeva and Stanislawska, 2008) plotted in Figure 3a demonstrates the 
transition from quiet to storm period during 17 to 24 January, 2012. The percentage root mean square

258 RMS deviation is plotted in Figure 3b. Figure 3c illustrates the standard deviation of GIM-TEC from 259 the reference Topex/Jason data. Figure 3d shows the bias of GIM-TEC and the Topex/Jason daily 260 averages. The bias (defined as averaged difference of JASON-2 VTEC minus global VTEC value) of 261 URTG map is positive, higher than the negative bias obtained in the most of other results (Figure 3d). 262 In principle, from the physical point of view, due to the difference in the orbits of two systems of TEC 263 products (the GPS constellation orbits the Earth at 20,200 km against 1,336 km of Topex/Jason), this 264 bias should be positive, containing the averaged electron content between the altimeter and the GPS constellation (Lee et al., 2013). However, and due to the well known positive bias in the altimeters calibration (of few TECUs affecting the TOPEX and JASON VTEC values see, for instance, (Brunini et al. 2005), it is not an issue to have a slightly negative bias. On the other hand, the GPS-TEC measurements are rare over the oceans with measurements made on the islands so that GIM-TEC 269 become less reliable in these areas dependent on a method of mapping functions used for filling gaps in missing GPS receiving data (Hernandez-Pajares et al., 2009). The standard deviation and RMS, in percent, (Figure 3b, c) illustrate the results of the preliminary RT URTG map which are of the same order of accuracy as a GIM-TEC forecast by IWAF system, Z1PG. The RMS deviation can amount up to $30 \%$ against the reference Topex/Jason data during the storm the both Z1PG and URTG errors exceeding the errors of other GIM-TEC maps computed with much more available observations in post-processing mode.

The W-index of the ionospheric quiet state, moderate disturbance, moderate storm or an intense storm is assigned according to the categories given in Table 3. The derivation of the $\mathrm{W}$-index map from GIM-TEC maps is specified in Appendix A. The W-index can also be computed using foF2, 279 instead of TEC in the equations A1-A9 (Gulyaeva et al., 2008). In IWAF system the W-index is computed using the source JPLR and UHRG maps and forecast of GIM-TEC with Eqns. (1-2).

Figure 4 illustrates usage of the W-index map for specification of 'quiet' day, 'positive' storm day (with dominant occurrence of storm-time index $\mathrm{W}=3$ and 4 on the map for a specific UT) and 
'negative' storm day (with reduced TEC regarding its quiet reference for majority of GIM-TEC cells 284 corresponding to index $\mathrm{W}=-3$ and -4 ). Here the occurrence (in percent of total number of 5,112 map 285 cells) of W-index of the said magnitudes is calculated hour-by-hour from UHRG (marked by W-u and $\mathrm{W}+\mathrm{u}$ ) and JPLR (marked by $\mathrm{W}-\mathrm{j}$ and $\mathrm{W}+\mathrm{j}$ ) maps for three periods selected from the Catalogue of the planetary Wp storms deduced and permanently upgraded in the framework of IWAF system (Gulyaeva and Stanislawska, 2010). The first period for 21-23 January, 2012, refers to part of the days shown in Figure 3 the maps representing winter in the North hemisphere and summer in the South hemisphere. The second period for 22-24 April, 2012, belongs to the equinox. The third period for 14-16 July, 2012, represents the summer/winter seasons in North/South hemisphere. Results of two GIM-TEC sources display consistent results starting from the quiet day with low occurrence of stormy W-index followed by an enhahced occurrence of positive storm indices with gradual developments of the negative storm afterwards. These are the typical two-phase ionosphere storm patterns (Mendillo, 2006) which imply injection of plasma by the solar wind into the ionosphere-plasmasphere system (positive phase of the ionospheric storm) followed by the plasma ejection (plasma depletion during the negative phase of the storm) towards the magnetosphere tail (Gulyaeva and Veselovsky, 2012).

We have computed the Root Mean Square Error, RMSE, for the residuals between predicted maps of TEC, foF2 and hmF2, and 'true' UHRG-based and JPLR-based maps for the periods shown in 300 Figure 4 and listed in Table 4. For each UT hour of day two vectors of grids were selected referring to 301 the local time, LT, noon and midnight longitudes. In total we combined 24 individual sets of data 302 (from maps for $0,1, \ldots, 23 \mathrm{~h} \mathrm{UT}$ ) each set for 71 latitude grids at $-87.5: 2.5: 87.5^{\circ} \mathrm{N}$ in a daily vector of 303 length $\mathrm{n}$ consisting of 1,704 elements denoted by $\vec{Y}$ for the 'true' maps and $\vec{X}$ for the prediction maps. 304 The RMSE in a vector form is equal to 
The IWAF system forecast with Eqns.1-2 for 1-day prediction (RMS1) and 2-day ahead prediction (RMS2) are compared with standard persistence model (RMS0) which assumes that 310 prediction is equal to the true value for the preceding day. Table 4 contains the results (a) for TEC 311 maps, (b) foF2 maps, (c) hmF2 maps. It follows from Table 4 that the RMSE is lower for the quiet (q) 312 day as should be expected because the harmonic analysis limited by 5 harmonic terms reproduces 313 more common (quiet) features of the four preceding days. The RMSE is growing at transition from 314 quiet day to the positive storm day (s+) because no assumption is put so far on an expected plasma 315 injection into the ionosphere-plasmasphere space. The RMSE is largest for the negative storm day (s-) 316 because the harmonic analysis for the preceding four days includes the day of the positive ionosphere 317 storm hence the residuals are growing at transition from the day of plasma input to the day of plasma 318 loss. The JPL maps errors are less than the UPC maps errors but the general trends are similar for the 319 both sets of the data. The IWAF results in total provide higher accuracy with less RMSE than the 320 persistence model.

\section{Results}

One of the objectives of this project is to provide the daily-hourly global foF2, hmF2 and Windex maps congruent with GIM-TEC product. An example of these maps along with the source UHRG map is provided in Figure 5 for 1200 UT of the storm day on October 1, 2012, which is analyzed in Table 2. The maps in Figure 5 are placed on the topographic map for longitudes from $0^{\circ}$ to $360^{\circ} \mathrm{E}$ so that for $1200 \mathrm{UT}$, the noon is shown at $0^{\circ} \mathrm{E}$, the midnight at $180^{\circ} \mathrm{E}$, and sunrise-sunset in 328 between.

Figure 5a demonstrates the diurnal variation of TEC around the globe with enhanced TEC and 330 foF2 around noon which is gradually decreased towards the nighttime. Minimum TEC equal to 2.4 331 TECU occurs around $0200 \mathrm{LT}$ at $60^{\circ} \mathrm{S}$, the maximum TEC equal to 102.1 TECU is reached at the 332 crest of the Equatorial Anomaly (EA) region. The specification of the ionospheric weather is provided 333 by the $\mathrm{W}$-index map in Figure 5 b.where the positive storm signatures $(\mathrm{W}=3$ and $\mathrm{W}=4)$ are 
concentrated at low latitudes the most of those in the evening sector. The decreased plasma density and electron content at the negative phase of the storm $(\mathrm{W}=-3$ and $\mathrm{W}=-4)$ are observed in the auroral and sub-auroral latitudes, and also near the equator around midnight. The foF2 map (Figure 5c) mirrors TEC features (Figure 5a) though the EA region is shifted to the afternoon, $1400 \mathrm{LT}$, and foF2 by night is remarkably decreased towards the poles. The map of the peak height (Figure 5d) is obtained using the empirical model of changes of hmF2 opposite to the foF2 changes (Gulyaeva, 2012) when the quiet reference is taken from the IRI-CCIR predictions. As a result, the higher hmF2 are seen along the midnight meridian. Near the noon equator, the lower hmF2 are obtained near the crests of EA. Another case for lower hmF2 occurred near the latitudes of the crests of EA but in the evening sector around 2000 LT. Remarkably mirrored (opposite) features can be captured in the hmF2 and W-index maps. These are due to hmF2 model (Gulyaeva, 2012) which is constructed by analysis of foF2 with W-index evaluation. Hence, while proper TEC and foF2 maps indicate neither the degree of a storm development nor its positive or negative signatures until relevant $\mathrm{W}$-index map is produced, the peak height hmF2 map can provide a picture for the expected features of a storm opposite to the pattern on $\mathrm{W}$-index map prior to its generation.

Numerical representation of the maps in IONEX format makes it possible to incorporate results in other operational communication and navigation systems (Goodman, 2005). In particular, the numerical maps of foF2 and hmF2 deduced with IRI-Plas code from GIM-TEC, could further serve as the IRI driving parameters for the IRI-Real Time implementation. Though the formal IRI code is limited by the ionosphere altitudes (below 1,500 km) excluding the plasmasphere part (Bilitza, 2001; Gulyaeva and Bilitza, 2012), the formal IRI is often used as the ionosphere background model with the Computerized Ionosphere Tomography, CIT (Bust and Mitchell, 2008). In such capacity the input of GIM-TEC adapted maps of foF2 and hmF2 (instead of CCIR or URSI maps) into the IRI code would speed up process of CIT convergence to 3-D ionosphere reconstruction from the navigation satellites signal measurements. 
360 predicted by IWAF system) is made for reconstruction of missed foF 2 and hmF2 ionosonde 361 observation and their forecast at the magnetic conjugate locations for the global network of ionosonde stations. Relevant procedures are included in the algorithm and applied online for more than 60 ionospheric observatories and their conjugate counterparts worldwide (Figure 6). The titles of the ionosonde stations, their geographic coordinates and geographic coordinates for their magnetic counterparts are provided at the "Ionospheric Weather' site (http://www.izmiran.ru/services/iweather/). The results of extracting the foF 2 and hmF2 values at the magnetic conjugate counterparts from the IWAF products are demonstrated in Figure $7 \mathrm{a}$, and $7 \mathrm{~b}$ for three days of the space weather storm on September 30, 1-2 October, 2012. The geographic and magnetic coordinates of five ionosondes, namely, Tromso (TR), Novosibirsk (NS), Boulder (BC), Port Stanley (PS), and Mawson (MW), and geographic/magnetic coordinates of their magnetic conjugate points (C.P.) are given in Table 5. 371 Projection of the magnetic field lines passing through the selected observatory and its corresponding magnetic conjugate point are plotted in Figure 6 in white lines. The relevant F2 layer peak parameters of foF 2 and hmF2 are analyzed during the three days of storm which occurred at the origin of a cascade of the series of the space weather storms at the beginning of October, 2012. The foF 2 and hmF2 measured at five observatories and predicted in their conjugate counterparts are presented in Figure 7. The planetary Wp index and the ring current Dst index are shown for a comparison (bottom sections). Both the 'true' values and the IWAF system prediction of foF2 and hmF2 at the conjugate points clearly demonstrate the space weather storm signatures. Thus, foF 2 values are decreased during October 1 when the peak of the ring current, Dst, index is decreased and planetary Wp index 380 increased. The data for this day are also analyzed in Table 2 and illustrated by the global maps in 381 Figure 5. The hmF2 behavior has become more irregular on October 1, particularly, at Port Stanley. 382 The small-scale variability of the F2 layer peak parameters at the magnetic conjugate low latitude 383 stations was discussed in more details by McNamara et al. (2008). The results of IWAF reconstruction of foF2 at the source observatories (crosses) are nearly coincident with the observations (circles). The 
shift of the diurnal profile of foF 2 and $\mathrm{hmF} 2$ at the origin observatory and their conjugate point closely

386 follows the difference in local time (longitude) at each pair of the ends of the magnetic field line. More 387 results of analysis of the ionosphere and plasmasphere storms with outcome of IWAF system are given 388 by Gulyaeva et al. $(2011 ; 2012)$.

The percentage occurrence of the W-index characteristics of the global 390 ionosphere/plasmasphere storms is plotted in Figure 8 for the period of 1999 to 2012, which covers 391 more than the total solar cycle shown by the monthly mean $10.7 \mathrm{~cm}$ solar radio flux, F10.7 (dashed curve). The daily peak occurrence of stormy $\mathrm{W}$-index $(\mathrm{W}= \pm 3$ and $\mathrm{W}= \pm 4)$, in percent, relative to the total number of cells (5112) on a map, is plotted (black line) for each day of observations, and their monthly average is provided (circles). Typical W-storm occurrence is about $10 \%$ of a globe surface but it can reach as much as $70 \%$ of the globe at the peak of the intense space weather storm. This type of W-index occurrence follows the variation of the solar activity demonstrating the global storm effects reduced from the solar maximum to solar minimum. The annual and seasonal components with equinoctial maxima, particularly pronounced at the high solar activity (Figure 8) deserve a special investigation and modeling for a reliable prediction of global ionospheric storms.

\section{Conclusions}

The variability of space weather and its potential impact on HF and satellite systems are important study areas with approaching the forthcoming solar maximum of the $24^{\text {th }}$ solar cycle expected in 2013. In this study, two important space weather products are introduced by the 405 Ionospheric Weather Assessment and Forecast (IWAF) system. The first product is the daily-hourly 406 global foF2, hmF2 and TEC maps that are based on IRI-Plas empirical climatic model adjusted to 407 GIM-TEC data. Hourly GIM maps from JPL, JPLR, and UPC, UHRG, serve as an input to IRI-Plas to 408 scale the coefficient set for actual space weather. In IWAF, W-index maps are produced from 1999 up409 to-date to represent the intensity and distribution of an ionospheric disturbance. W-index proved itself 
410 to be an excellent proxy for storm classification and analysis in terms of coupling of solar wind into 411 the Earth's ionosphere and plasmasphere.

412 The second important product of IWAF is the prediction of TEC on a global scale one day or 413 two days ahead through a forecast model which is represented in spherical harmonics functions. The 414 accuracy of forecasted TEC maps are of the same order as IGS forecast products from various data 415 analysis centers. With production of the IWAF forecast of TEC, foF2 and hmF2 maps, the near real416 time assessment and forecast of these parameters are provided for any location on the globe including 417 the missed observations at the global ionosonde network and their magnetic conjugate locations.

IWAF services can be reached at Ionospheric Weather Service of IZMIRAN at

419 http://www.izmiran.ru/services/iweather/ or at IONOLAB website at www.ionolab.org. The foF2, $420 \mathrm{hmF} 2$, TEC and Wp movies for selected collection of the severe ionospheric and plasmaspheric storms 421 since 2001 are provided in youtube under IONOLAB or at IONOLAB website under 'videos'.

\section{Acknowledgements}

The UPC, JPL and other GIM-TEC maps are provided by Iono-WG of GNSS at the web site of ftp://cddis.gsfc.nasa.gov/gps/products/ionex/. The TOPEX/Jason data are provided by JPL at ftp://podaac-ftp.jpl.nasa.gov/. The ionosonde data are provided at http://spidr.ngdc.noaa.gov/spidr/. The kp-index is provided at http://www-app3.gfz-potsdam.de/kp_index/. The IWAF system is mirrored at IZMIRAN web site http://www.izmiran.ru/services/iweather/ and IONOLAB web site http://www.ionolab.org/ to guarantee the proposed service for a potential user. The assistance of Umut Sezen and Onur Cilibas of IONOLAB, Lukasz Tomasik of SRC and Ljubov Poustovalova of 431 IZMIRAN in web products design, and Alberto Garcia-Rigo of UPC in IGS ionospheric combination 432 is gratefully acknowledged. This study is supported by the joint grant from TUBITAK 110E296 and 433 RFBR 11-02-91370-CT_a, TUBITAK 112E568 and RFBR 13-02-91370-CT_a. The valuable 434 comments and suggestions of the Editor and Reviewers are gratefully appreciated by the authors. 


\section{References}

437 Araujo-Pradere, E.A., Fuller-Rowell, T.J., Codrescu, M.V., 2002. STORM: An empirical storm-time 438 ionospheric correction model. 1. Model description, Radio Sci., 37(5), 1070, doi:10.1029/2001RS002467.

Azpilicueta, F., and Brunini, C., 2008. Analysis of the bias between TOPEX and GPS vTEC determinations, Journal of Geodesy, 83(2), 121-127, 2008.

Bilitza, D., 2001. International Reference Ionosphere 2000, Radio Science. 36, 261-275, doi:10.1029/2000RS002432.

Blanch, E., and Altadill, D., 2013. Midlatitude F region peak height changes in response to interplanetary magnetic field conditions and modeling results. J. Geophys. Res., 117, A12311, doi:10.1029/2012JA018009.

Bradley, P. A., Stanislawska, I., Juchnikowski, G., 2009. Options for mapping foF2, Adv. Space Res., 43, 1776-1779.

Brunini, C., Meza, A., Bosch, W., 2005. Temporal and spatial variability of the bias between TOPEXand GPS-derived total electron content, Journal of Geodesy, 79(4-5), 175-188, doi:10.1007/s00190-005-0448-z.

Bust, G.S., Mitchell, C.N., 2008. History, current state, and future directions of ionospheric imaging, Rev. Geophys., 46, RG1003, doi:10.1029/2006RG000212.

Dow, J.M., Neilan, R.E., Rizos, C., 2009. The International GNSS Service in a changing landscape of Global Navigation Satellite Systems, Journal of Geodesy, 83, 191-198. 
461 Garcia-Rigo, A., Monte, E., Hernandez-Pajares, M., Juan, J.M., Sanz, J., Aragon-Angel, A., Salazar, 462 D., 2011. Global prediction of the vertical total electron content of the ionosphere based on GPS 463 data. Radio Sci., 46, RS0D25, doi:10.1029/2010RS004643.

464 Goodman, J.M., 2005. Operational communication systems and relationships to the ionosphere and 465 space weather, Adv. Space Res., 36, 2241-2252.

466 Gulyaeva, T.L., Stanislawska, I., Tomasik, M., 2008. Ionospheric weather: Cloning missed foF2 467 observations for derivation of variability index. Annales Geophysicae, 26(2), 315-321.

468 Gulyaeva, T.L., Stanislawska, I., 2008. Derivation of a planetary ionospheric storm index, Annales $469 \quad$ Geophysicae, 26(9), 2645-2648.

470 Gulyaeva, T.L., Arikan, F., Delay, S., 2009. Scale factor mitigating non-compliance of double 471 frequency altimeter measurements of the ionospheric electron content over the oceans with GPS472

473 Gulyaeva, T.L,. Stanislawska, I., 2010. Magnetosphere associated storms and autonomous storms in 474 the ionosphere-plasmasphere environment. J. Atmos. Solar-Terr. Phys., 72, 90-96, doi:10.1016/j.jastp.2009.100.012.

Gulyaeva, T.L., Arikan, F., Stanislawska, I., 2011. Inter-hemispheric Imaging of the Ionosphere with the upgraded IRI-Plas model during the space weather storms, Earth, Planets and Space, 63(8), 929-939, doi: 10.5047/eps.20110.040.007.

Gulyaeva, T., 2012. Empirical model of ionospheric storm effects on the F2 layer peak height associated with changes of peak electron density, J. Geophys. Res., 117, A02302, doi:10.1029/2011JA017158.

Gulyaeva, T., Veselovsky, I.S., 2012. Two-phase storm profile of global electron content in the ionosphere and plasmasphere of the Earth, J. Geophys. Res., 117, .A9, A09325, doi:10.1029/2012JA018017. 
Gulyaeva, T.L., Arikan, F., Stanislawska, I., Poustovalova, L.V., 2012. Symmetry and asymmetry of ionospheric weather at magnetic conjugate points for two midlatitude observatories, Adv. Space Res., doi:10.1016/j.asr.20120.090.038.

Gulyaeva, T.L., Bilitza, D., 2012. Towards ISO standard earth ionosphere and plasmasphere model, in New Developments in the Standard Model, edited by R. J. Larsen, pp. 1-39, NOVA, Hauppauge, New York, https://www.novapublishers.com/catalog/product_info.php?products_id=35812.

Hernandez-Pajares, M., Juan, J.M., Sanz, J., Garcia-Rigo, A., Feltens, J., Komjathy, A., Schaer, S.C., Krankowski, A., 2009. The IGS VTEC maps: A reliable source of ionospheric information since 1998, Journal of Geodesy, 83(3-4), 263-275.

Jakowski, N., Heise, S., Wehrenpfennig, A., Schlüter, S., Reimer, R., 2002. GPS/GLONASS-based TEC measurements as a contributor for space weather forecast, J. Atmos. Solar-Terrestrial Phys., 64, 729-735.

Jones, W.B., Gallet, R.M., 1962. The representation of diurnal and geographic variations of ionospheric data by numerical methods, Telecomm. J., 29, 129-149.

Lee, H.-B., Jee, G., Kim, Y.H., and Shim, J.S., 2013. Characteristics of global plasmaspheric TEC in comparison with the ionosphere simultaneously observed by Jason-1 satellite. J. Geophys. Res. Space Physics, 118, doi:10.1002/jgra.50130.

Manucci, A.J., Wilson, B.D., Yuan, D.N., Ho, C.M., Lindqwister, U.J., and Runge, T.F., 1998. A global mapping technique for GPS-derived ionospheric total electron content measurements. Radio Sci., 33, 565-582.

Maruyama, T., 2010. Solar proxies pertaining to empirical ionospheric total electron content models, J. Geophys. Res., 115, A04306, doi:10.1029/2009JA014890.

McNamara, L.F., Retterer, J.M., Abdu, M.A., Batista, I.S., Reinisch, B.W., 2008. F2 Peak parameters, drifts and spread $\mathrm{F}$ derived from digisonde ionograms for the COPEX campaign in Brazil, J. Atmos. Solar-Terrestrial Phys. 70, 1144-1158. 
510 Mendillo, M., 2006. Storms in the ionosphere: Patterns and processes for total electron content. $511 \quad$ Reviews of Geophys., 44, RG2001, doi:10.1029/2005RG000193.

512 Orus R., Hernandez-Pajares, M., Juan, J.M., Sanz, J., 2005. Improvement of global ionospheric VTEC 513 maps by using kriging interpolation technique, J. Atmos. Solar-Terrestrial Phys. 67, 1598-1609.

514 Rose, R.B., 1993. A high-latitude ionospheric disturbance impact assessment system, Radio Sci., $515 \quad 28(1), 97-104$.

516 Rush, C., Fox, M., Bilitza, D., Davies, K., McNamara, L., Stewart, F., PoKempner, M., 1989. 517 Ionospheric mapping - an update of foF2 coefficients, Telecomm J., 56, $179-182$.

518 Schaer, S., Gurtner, W., and Feltens, J., 1998. IONEX: The IONosphere Map Exchange format 519 Version 1, in: Proc. of the IGS Analysis Center Workshop, ed. By Dow, J.M., Kouba, J., and 520 Springer, T., pp.233-247, Darmstadt, Germany.

521 Smith, D.A., Araujo-Pradere, E.A., Minter, C., Fuller-Rowell, T. A, 2008. Comprehensive evaluation 522 of the errors inherent in the use of a two-dimensional shell for modeling the ionosphere. Radio Sci., 43, RS6008, doi:10.1029/2007RS003769.

524 Somsikov, V.M., 2011. Solar terminator and dynamic phenomena in the atmosphere: A review, 525 Geomagnetism and Aeronomy, 51(6), 707-719, doi: 2011.10.1134/S0016793211060168.

526 Vodjannikov, V., Gordienko, G., 2011. A statistical method for reconstruction of missed observations and foF2 short-term prediction, IEEE Xplore, General Assembly and Scientific Symposium, 2011

Zolesi, B., Cander, Lj R., 2000. Evolution of the ionospheric mapping and modelling during the last 
The $\mathrm{W}$-index computation for a rectangular region defined by $\left(\theta_{\mathrm{i}}, \phi_{\mathrm{i}}\right)$ to $\left(\theta_{\mathrm{s}}, \phi_{\mathrm{s}}\right)$ is provided for

538 the increments in $\theta$ and in $\phi$ given as $\Delta \theta$ and $\Delta \phi$, respectively. The grid structure is arranged such that $539\left(\theta_{\mathrm{i}}, \phi_{\mathrm{i}}\right)$ forms the initial grid point (lower left corner of the rectangular region) and the rectangular 540 region extends towards north and east. The grid ends at $\left(\theta_{\mathrm{s}}, \phi_{\mathrm{s}}\right)$ as the upper right corner of the 541 rectangular region. The number of grid points in $\theta$ and in $\phi$ can be obtained as

$$
\mathrm{N}_{\theta}=\left|\theta_{\mathrm{s}}-\theta_{\mathrm{i}}\right| / \Delta \theta+1
$$

$$
\mathrm{N}_{\phi}=\left|\phi_{\mathrm{s}}-\phi_{\mathrm{i}}\right| / \Delta \phi+1
$$

547 Similarly,

$$
\Delta \phi=\left|\phi_{\mathrm{s}}-\phi_{\mathrm{i}}\right| /\left(\mathrm{N}_{\phi}-1\right)
$$

$$
\theta=\theta_{\mathrm{i}}+\Delta \theta\left(\mathrm{n}_{\theta}-1\right)
$$

$$
\phi=\phi_{\mathrm{i}}+\Delta \phi\left(\mathrm{n}_{\phi}-1\right)
$$


560 where $1 \leq \mathrm{n}_{\theta} \leq \mathrm{N}_{\theta}$ and $1 \leq \mathrm{n}_{\phi} \leq \mathrm{N}_{\phi}$. If, for a given day d, TEC values on such a rectangular grid are 561 updated for a total of $\mathrm{N}_{\mathrm{T}}$ times with incremental steps of time index, $\mathrm{n}_{\mathrm{T}}$ (where $1 \leq \mathrm{n}_{\mathrm{T}} \leq \mathrm{N}_{\mathrm{T}}$ ), then the 562 TEC value at any point $(\theta, \phi)$ and time index $\mathrm{n}_{\mathrm{T}}$ can be represented using a lexicographical index 563 notation as

$$
\mathrm{X}_{\mathrm{d}}=\left[\mathrm{x}_{\mathrm{d}}(1) \ldots \mathrm{x}_{\mathrm{d}}(l) \ldots \mathrm{x}_{\mathrm{d}}\left(\mathrm{N}_{\theta} \mathrm{N}_{\phi} \mathrm{N}_{\mathrm{T}}\right)\right]^{\mathrm{T}}
$$

where the superscript $\mathrm{T}$ is the transpose operator and the index $l$ is defined as

$$
l=\mathrm{n}_{\theta}+\left(\mathrm{n}_{\phi}-1\right) \mathrm{N}_{\theta}+\left(\mathrm{n}_{\mathrm{T}}-1\right) \mathrm{N}_{\theta} \mathrm{N}_{\phi}
$$

571 and $1 \leq l \leq \mathrm{N}_{\theta} \mathrm{N}_{\phi} \mathrm{N}_{\mathrm{T}}$. For the total number of days $N_{d_{d_{-}-d_{i}}}$ from day $\mathrm{d}_{\mathrm{i}}$ to day $\mathrm{d}_{\mathrm{s}}$ prior to the day $\mathrm{d}$, the 572 TEC values can be arranged in a matrix as

$$
X_{d_{s}-d_{i}}=\left[\begin{array}{lll}
x_{d_{i}} \ldots & x_{d_{s}}
\end{array}\right]_{\left(N_{\theta} N_{\phi} N_{T}\right) \times\left(N_{d_{s}-d_{i}}\right)}
$$

Let the vector

$$
x_{m ; d_{s}-d_{i}}=\left[x_{m ; d_{s}-d_{i}}(1) \ldots x_{m ; d_{s}-d_{i}}(l) \ldots x_{m ; d_{s}-d_{i}}\left(N_{\theta} N_{\phi} N_{T}\right)\right]^{T}
$$

580 denote the median of $x_{d_{s}-d_{i}}$ across each row as

$$
x_{m ; d_{s}-d_{i}}(l)=\text { median } \quad\left(x_{d_{i}}(l) \ldots x_{d_{s}}(l)\right)
$$


584 The deviation TEC value from the median TEC of $N_{d_{s}-d_{i}}$ number of days prior to day $\mathrm{d}$ is expressed 585 as

586

$$
D_{d}(l)=\log \left(\frac{x_{d}(l)}{x_{m ; d_{s}-d_{i}}(l)}\right)
$$

588 The W-index derivation is applied to produce W-index map in IONEX format from the source Global 589 Ionospheric Map, GIM-TEC.

607 Table 1. Acronyms used in the paper and their meaning 


\begin{tabular}{|l|l|}
\hline Acronym & \multicolumn{1}{|c|}{ Content } \\
\hline CCIR & Comité Consultatif International des Radiocommunications \\
\hline CDDIS & Crustal Dynamics Data Information System \\
\hline CIT & Computerized Ionospheric Tomography \\
\hline CODE & Center for Orbit Determination in Europe, University of Bern \\
\hline C.P. & Magnetic Conjugate Points \\
\hline EHRG & ESA-ESTEC generated GIM-TEC \\
\hline HF & High Frequency from 30 MHz to $3 \mathrm{MHz}$ \\
\hline gAGE/UPC & Technical University of Catalonia, Spain \\
\hline GIM-TEC & Global Ionospheric Map of Total Electron Content \\
\hline GNSS & Global Navigation Satellite System \\
\hline GPS & Global Positioning System \\
\hline IGS & International Geodynamic Service \\
\hline IGRG & IONEX file containing the combined IGS lonosphere maps \\
\hline IONEX & IONosphere map EXchange format \\
\hline Iono-WG & Ionospheric Working Group of GNSS service \\
\hline IRI-Plas & International Reference Ionosphere extended to Plasmasphere \\
\hline ITU-R & International Telecommunication Union, Radio Division \\
\hline IWAF & Ionospheric Weather Assessment and Forecast system \\
\hline JPLR & Jet Propulsion Laboratory Rapid (preliminary) GIM-TEC \\
\hline JPLG & Jet Propulsion Laboratory final GIM-TEC \\
\hline M3000F2 & Radio wave Propagation Factor at a distance of 3,000 km \\
\hline RT & Real Time \\
\hline TEC & Total Electron Content \\
\hline TECU & TEC Unit; 1 TECU = 1 $\times 10^{16}$ el/m ${ }^{2}$ \\
\hline UHRG & Hourly Rapid UPC product of GIM-TEC \\
\hline URTG & Preliminary UPC product of GIM-TEC \\
\hline U2PG & 2-day forecast of UPC GIM-TEC \\
\hline URSI & International Union of Radio Science \\
\hline VTEC & Vertical Total Electron Content \\
\hline
\end{tabular}


617 Table 2. Relative error of 1-day forecast $\left(\delta_{1}\right)$ and 2-days ahead forecast $\left(\delta_{2}\right)$ of TEC, foF2 and hmF2 618 maps regarding to the reference UHRG 'true' maps for the worst case storm conditions on October 1, 6192012.

620

\begin{tabular}{|c|c|c|c|c|c|c|}
\hline \multirow{2}{*}{$\begin{array}{c}\text { Hours } \\
\text { LT }\end{array}$} & \multicolumn{2}{|c|}{ foF2 } & \multicolumn{2}{|c|}{$h m F 2$} & \multicolumn{2}{|c|}{$T E C$} \\
\hline & $\delta_{1}$ & $\delta_{2}$ & $\delta_{1}$ & $\delta_{2}$ & $\delta_{1}$ & $\delta_{2}$ \\
\hline 0000 & 0.0185 & 0.0174 & 0.0218 & 0.0203 & 0.0199 & 0.0221 \\
\hline 0100 & 0.0207 & 0.0192 & 0.0231 & 0.0221 & 0.0144 & 0.0191 \\
\hline 0200 & 0.0117 & 0.0130 & 0.0260 & 0.0263 & 0.0103 & 0.0113 \\
\hline 0300 & 0.0085 & 0.0086 & 0.0252 & 0.0261 & 0.0078 & 0.0076 \\
\hline 0400 & 0.0077 & 0.0076 & 0.0273 & 0.0268 & 0.0076 & 0.0072 \\
\hline 0500 & 0.0080 & 0.0078 & 0.0336 & 0.0310 & 0.0088 & 0.0076 \\
\hline 0600 & 0.0108 & 0.0101 & 0.0208 & 0.0192 & 0.0106 & 0.0097 \\
\hline 0700 & 0.0287 & 0.0327 & 0.0120 & 0.0150 & 0.0207 & 0.0194 \\
\hline 0800 & 0.0296 & 0.0294 & 0.0111 & 0.0119 & 0.0358 & 0.0349 \\
\hline 0900 & 0.0300 & 0.0333 & 0.0120 & 0.0132 & 0.0316 & 0.0340 \\
\hline 1000 & 0.0305 & 0.0302 & 0.0176 & 0.0167 & 0.0301 & 0.0303 \\
\hline 1100 & 0.0259 & 0.0292 & 0.0187 & 0.0190 & 0.0288 & 0.0327 \\
\hline 1200 & 0.0253 & 0.0265 & 0.0214 & 0.0224 & 0.0265 & 0.0350 \\
\hline 1300 & 0.0251 & 0.0241 & 0.0243 & 0.0242 & 0.0261 & 0.0338 \\
\hline 1400 & 0.0254 & 0.0244 & 0.0242 & 0.0224 & 0.0258 & 0.0339 \\
\hline 1500 & 0.0251 & 0.0260 & 0.0222 & 0.0201 & 0.0263 & 0.0277 \\
\hline 1600 & 0.0259 & 0.0243 & 0.0186 & 0.0218 & 0.0286 & 0.0328 \\
\hline 1700 & 0.0265 & 0.0296 & 0.0178 & 0.0191 & 0.0298 & 0.0306 \\
\hline 1800 & 0.0287 & 0.0295 & 0.0203 & 0.0221 & 0.0308 & 0.0361 \\
\hline 1900 & 0.0250 & 0.0300 & 0.0272 & 0.0350 & 0.0224 & 0.0249 \\
\hline 2000 & 0.0229 & 0.0248 & 0.0261 & 0.0268 & 0.0219 & 0.0208 \\
\hline 2100 & 0.0194 & 0.0204 & 0.0238 & 0.0246 & 0.0199 & 0.0233 \\
\hline 2200 & 0.0162 & 0.0161 & 0.0213 & 0.0244 & 0.0178 & 0.0266 \\
\hline 2300 & 0.0155 & 0.0141 & 0.0193 & 0.0194 & 0.0178 & 0.0159 \\
\hline Average & 0.0213 & 0.0220 & 0.0215 & 0.0221 & 0.0217 & 0.0241 \\
\hline
\end{tabular}

621

622

623

624

625

626

627 
Table 3. Categories of the ionospheric weather $\mathrm{W}$-index corresponding to the logarithmic deviation

629 from the median.

$\mathrm{D}_{\mathrm{d}}(l) \quad$ W Categories of the Ionospheric State

\begin{tabular}{ccc}
\hline $\mathrm{D}_{\mathrm{d}}(l)>0.301$ & 4 & Intense positive $\mathrm{W}^{+}$storm \\
$0.155<\mathrm{D}_{\mathrm{d}}(l) \leq 0.301$ & 3 & Moderate $\mathrm{W}^{+}$storm or $\mathrm{W}^{+}$substorm \\
$0.046<\mathrm{D}_{\mathrm{d}}(l) \leq 0.155$ & 2 & Weak $\mathrm{W}^{+}$disturbance \\
$0.0<\mathrm{D}_{\mathrm{d}}(l) \leq 0.46$ & 1 & Quiet $\mathrm{W}^{+}$state \\
$\mathrm{D}_{\mathrm{d}}(l)=0$ & 0 & Reference Quiet state \\
$-0.046 \leq \mathrm{D}_{\mathrm{d}}(l)<0.0$ & -1 & Quiet $\mathrm{W}^{-}$state \\
$-0.155 \leq \mathrm{D}_{\mathrm{d}}(l)<-0.046$ & -2 & $\mathrm{Weak} \mathrm{W}^{-}$disturbance \\
$-0.301 \leq \mathrm{D}_{\mathrm{d}}(l)<-0.155$ & -3 & Moderate $\mathrm{W}^{-}$storm or $\mathrm{W}^{-}$substorm \\
$\mathrm{D}_{\mathrm{d}}(l)<-0.301$ & -4 & Intense negative $\mathrm{W}^{-}$storm
\end{tabular}

630

631

632 Table 4. Validation of IWAF system prediction of GIM-TEC (a), foF2 (b), and hmF2 (c) maps 1-day

633 ahead (1) and 2-days ahead (2) along with the standard persistence model (0) which assumes that

634 prediction is equal to data of numerical map for the preceding day. Daily averaged noon and midnight

635 data are selected from 24 hourly UT maps, for quiet (q) day, dominant positive storm day (s+), and

636 dominant negative storm day (s-) for three months of 2012 (January, April, and July) representing

637 different seasons.

638 (a) Mean TEC, RMS [TECU].

\begin{tabular}{|c|c|c|c|c|c|c|c|c|}
\hline \multirow{3}{*}{$\begin{array}{l}\text { Date, } \\
2012\end{array}$} & \multicolumn{4}{|c|}{ Midnight } & \multicolumn{4}{|c|}{ Noon } \\
\hline & \multicolumn{8}{|c|}{ UPC } \\
\hline & Mean & RMS0 & RMS1 & RMS2 & Mean & RMS0 & RMS1 & RMS2 \\
\hline \multirow{3}{*}{$\begin{array}{c}\operatorname{Jan} 21 \mathrm{q} \\
22 \mathrm{~s}+ \\
23 \mathrm{~s}-\end{array}$} & 15.0 & 3.00 & 2.95 & 3.16 & 30.9 & 4.26 & 3.70 & 3.82 \\
\hline & 16.4 & 3.52 & 3.50 & 3.76 & 33.4 & 5.61 & 5.34 & 5.58 \\
\hline & 15.0 & 4.65 & 4.34 & 4.60 & 31.9 & 7.45 & 5.73 & 5.86 \\
\hline \multirow{3}{*}{$\begin{array}{r}\text { Apr } 22 q \\
23 s+ \\
24 s-\end{array}$} & 15.7 & 4.94 & 3.92 & 4.06 & 36.5 & 6.95 & 5.32 & 5.41 \\
\hline & 16.3 & 6.85 & 4.90 & 4.85 & 38.0 & 7.68 & 5.43 & 5.44 \\
\hline & 14.7 & 7.21 & 5.54 & 5.39 & 34.7 & 8.62 & 7.09 & 7.10 \\
\hline \multirow{3}{*}{$\begin{array}{c}\text { Jul } 14 q \\
15 s+ \\
16 s- \\
\end{array}$} & 10.5 & 2.22 & 2.13 & 2.39 & 21.7 & 3.87 & 4.52 & 5.02 \\
\hline & 11.6 & 4.23 & 3.61 & 3.49 & 23.6 & 6.89 & 6.10 & 6.01 \\
\hline & 8.6 & 4.82 & 4.02 & 4.29 & 19.2 & 8.36 & 6.73 & 6.93 \\
\hline Average & 13.8 & 4.60 & 3.88 & 4.00 & 30.0 & 6.63 & 5.55 & 5.69 \\
\hline \multirow{2}{*}{$\begin{array}{l}\text { Date, } \\
2012\end{array}$} & \multicolumn{8}{|c|}{ JPL } \\
\hline & Mean & RMS0 & RMS1 & RMS2 & Mean & RMS0 & RMS1 & RMS2 \\
\hline $\operatorname{Jan} 21 \mathrm{q}$ & 14.9 & 2.68 & 2.03 & 2.22 & 32.2 & 3.72 & 3.09 & 3.20 \\
\hline $22 s+$ & 15.4 & 3.33 & 3.35 & 3.52 & 34.7 & 6.64 & 6.24 & 6.25 \\
\hline
\end{tabular}




\begin{tabular}{|r|r|r|r|r|r|r|r|r|}
\hline 23s- & 13.6 & 4.17 & 4.15 & 4.43 & 32.7 & 7.98 & 6.33 & 6.70 \\
\hline Apr 22q & 17.1 & 4.01 & 2.87 & 2.79 & 38.9 & 6.16 & 4.96 & 5.15 \\
\cline { 2 - 9 } $23 \mathrm{~s}+$ & 16.2 & 3.85 & 3.65 & 3.87 & 39.9 & 5.43 & 3.86 & 4.18 \\
\cline { 2 - 9 } $24 \mathrm{~s}-$ & 15.3 & 5.50 & 4.58 & 4.54 & 36.9 & 8.68 & 7.55 & 7.44 \\
\hline Jul 14q & 12.5 & 2.34 & 2.31 & 2.62 & 24.7 & 4.03 & 4.71 & 5.28 \\
\cline { 2 - 9 } $15 \mathrm{~s}+$ & 12.9 & 4.41 & 3.61 & 3.44 & 26.6 & 6.75 & 6.08 & 6.00 \\
\cline { 2 - 9 } 16s- & 10.5 & 4.66 & 3.92 & 4.20 & 21.9 & 8.12 & 6.51 & 6.80 \\
\hline Average & 14.3 & 3.88 & 3.39 & 3.51 & 32.1 & 6.39 & 50.48 & 5.67 \\
\hline
\end{tabular}

640

(b) Mean foF2, RMSE [MHz].

\begin{tabular}{|c|c|c|c|c|c|c|c|c|}
\hline \multirow{3}{*}{$\begin{array}{l}\text { Date, } \\
2012\end{array}$} & \multicolumn{4}{|c|}{ Midnight } & \multicolumn{4}{|c|}{ Noon } \\
\hline & \multicolumn{8}{|c|}{ UPC } \\
\hline & Mean & RMS0 & RMS1 & RMS2 & Mean & RMS0 & RMS1 & RMS2 \\
\hline \multirow{3}{*}{$\begin{array}{r}\operatorname{Jan} 21 \mathrm{q} \\
\frac{22}{23} \mathrm{~s}+ \\
\end{array}$} & 4.9 & 0.48 & 0.48 & .52 & 7.6 & 0.51 & 0.44 & 0.46 \\
\hline & 5.2 & 0.60 & 0.60 & 0.64 & 7.9 & 0.70 & 0.68 & 0.71 \\
\hline & 4.9 & 0.80 & 0.60 & 0.79 & 7.6 & 0.95 & 0.70 & 0.72 \\
\hline \multirow{3}{*}{$\begin{array}{r}\text { Apr } 22 \mathrm{q} \\
23 \mathrm{~s}+ \\
\underline{24} \mathrm{~s}-\end{array}$} & 5.4 & 0.84 & 0.64 & 0.65 & 8.3 & 0.78 & 0.60 & 0.63 \\
\hline & 5.5 & 1.19 & 0.86 & 0.84 & 8.5 & 1.02 & 0.73 & 0.71 \\
\hline & 5.1 & 1.22 & 0.93 & 0.90 & 8.0 & 0.96 & 0.78 & 0.80 \\
\hline \multirow{3}{*}{$\begin{array}{r}\text { Jul 14q } \\
15 \mathrm{~s}+ \\
16 \mathrm{~s}- \\
\end{array}$} & 4.2 & 0.95 & 0.95 & 0.94 & 6.6 & 0.57 & 0.66 & 0.73 \\
\hline & 4.5 & 0.92 & 0.80 & 0.77 & 6.9 & 1.04 & 0.93 & 0.92 \\
\hline & 3.9 & 0.98 & 0.92 & 0.99 & 6.1 & 1.19 & 0.94 & 0.98 \\
\hline Average & 4.8 & 0.89 & 0.77 & 0.78 & 7.5 & 0.86 & 0.72 & 0.74 \\
\hline \multirow{2}{*}{$\begin{array}{l}\text { Date, } \\
2012\end{array}$} & \multicolumn{8}{|c|}{ JPL } \\
\hline & Mean & RMS0 & RMS1 & RMS2 & Mean & RMS0 & RMS1 & RMS2 \\
\hline \multirow{3}{*}{$\begin{array}{r}\text { Jan } 21 \mathrm{q} \\
\frac{22}{23} \mathrm{~s}+ \\
\mathrm{23}-\end{array}$} & 5.0 & 0.41 & 0.35 & 0.38 & 7.7 & 0.44 & 0.38 & 0.40 \\
\hline & 5.1 & 0.58 & 0.60 & 0.64 & 8.0 & 0.77 & 0.60 & 0.77 \\
\hline & 4.7 & 0.73 & 0.71 & 0.76 & 7.7 & 0.95 & 0.74 & 0.78 \\
\hline \multirow{3}{*}{$\begin{array}{r}\text { Apr } 22 \mathrm{q} \\
23 \mathrm{~s}+ \\
24 \mathrm{~s}-\end{array}$} & 5.5 & 0.61 & 0.45 & 0.44 & 8.6 & 0.70 & 0.56 & 0.59 \\
\hline & 5.4 & 0.62 & 0.56 & 0.59 & 8.6 & 0.65 & 0.46 & 0.49 \\
\hline & 5.2 & 0.83 & 0.71 & 0.71 & 8.2 & 0.98 & 0.88 & 0.88 \\
\hline \multirow{3}{*}{$\begin{array}{r}\text { Jul } 14 q \\
15 s+ \\
16 s-\end{array}$} & 4.7 & 0.46 & 0.46 & 0.51 & 7.1 & 0.59 & 0.68 & 0.77 \\
\hline & 4.7 & 0.89 & 0.76 & 0.73 & 7.3 & 0.89 & 0.85 & 0.86 \\
\hline & 4.2 & 0.88 & 0.79 & 0.86 & 6.6 & 1.10 & 0.82 & 0.86 \\
\hline Average & 4.9 & 0.67 & 0.60 & 0.62 & 7.8 & 0.79 & 0.68 & 0.71 \\
\hline
\end{tabular}

641

(c) Mean hmF2, RMSE [km].

\begin{tabular}{|r|r|r|r|r|r|r|r|r|}
\hline & \multicolumn{9}{|c|}{ Midnight } & \multicolumn{5}{c|}{ Noon } \\
\cline { 2 - 10 } Date, \\
\cline { 2 - 10 } 2012 & \multicolumn{9}{|c|}{ Uean } & RMS0 & RMS1 & RMS2 & Mean & RMS0 & RMS1 & RMS2 \\
\hline Jan 21q & 351 & 10.3 & 10.2 & 10.8 & 322 & 7.9 & 6.1 & 6.2 \\
\cline { 2 - 10 } 22s + & 347 & 13.7 & 13.2 & 13.7 & 319 & 9.8 & 9.9 & 10.3 \\
\cline { 2 - 10 } 23s- & 351 & 19.2 & 19.5 & 20.2 & 321 & 13.3 & 12.5 & 13.3 \\
\hline Apr 22q & 364 & 18.5 & 14.6 & 14.7 & 333 & 11.4 & 8.8 & 9.4 \\
\cline { 2 - 10 } $23 \mathrm{~s}+$ & 371 & 22.0 & 17.3 & 17.4 & 333 & 14.1 & 9.9 & 9.7 \\
\cline { 2 - 9 } 24s- & 367 & 27.7 & 21.5 & 20.4 & 335 & 19.9 & 16.8 & 16.5 \\
\hline
\end{tabular}




\begin{tabular}{|r|r|r|r|r|r|r|r|r|}
\hline Jul 14q & 351 & 11.5 & 11.7 & 12.8 & 318 & 8.0 & 9.0 & 10.0 \\
\cline { 2 - 9 } $15 \mathrm{~s}+$ & 344 & 23.2 & 21.4 & 21.3 & 315 & 18.4 & 14.6 & 13.9 \\
\cline { 2 - 9 } 16s - & 359 & 27.2 & 25.0 & 26.2 & 324 & 22.8 & 17.7 & 17.6 \\
\hline Average & 356 & 19.3 & 17.2 & 17.5 & 324 & 14.0 & 11.7 & 11.9 \\
\hline Date, & \multicolumn{7}{|c|}{ JPL } \\
\cline { 2 - 10 } 2012 & Mean & RMS0 & RMS1 & RMS2 & Mean & RMS0 & RMS1 & RMS2 \\
\hline Jan 21q & 345 & 8.2 & 7.6 & 8.4 & 317 & 6.1 & 4.8 & 5.0 \\
\cline { 2 - 10 }$\underline{22} \mathrm{~s}+$ & 343 & 12.4 & 12.9 & 13.5 & 314 & 10.6 & 10.2 & 10.3 \\
\cline { 2 - 10 } $23 \mathrm{~s}-$ & 349 & 15.0 & 15.8 & 17.0 & 316 & 13.3 & 12.7 & 13.6 \\
\hline Apr 22q & 358 & 13.3 & 10.4 & 10.5 & 328 & 10.6 & 8.0 & 8.2 \\
\cline { 2 - 10 } $23 \mathrm{~s}+$ & 362 & 12.1 & 11.7 & 12.6 & 327 & 9.0 & 6.7 & 7.3 \\
\cline { 2 - 10 }$\underline{24 s-}$ & 363 & 17.2 & 14.9 & 15.2 & 331 & 15.7 & 15.5 & 16.0 \\
\hline Jul 14q & 341 & 11.1 & 11.1 & 12.1 & 314 & 8.9 & 9.8 & 10.7 \\
\cline { 2 - 9 } $15 \mathrm{~s}+$ & 339 & 19.5 & 17.6 & 17.7 & 310 & 15.3 & 11.9 & 11.5 \\
\cline { 2 - 9 } 16s- & 348 & 23.0 & 17.2 & 17.9 & 318 & 20.8 & 16.6 & 16.3 \\
\hline Average & 350 & 14.6 & 13.2 & 13.9 & 319 & 12.3 & 10.7 & 11.0 \\
\hline
\end{tabular}

644 Table 5. Geographic coordinates of five ionosondes and geographic coordinates of their magnetic 645 conjugate counterparts and the magnetic coordinates of the both.

646

\begin{tabular}{|l|l|l|l|l|l|l|}
\hline \multirow{2}{*}{ Station } & \multicolumn{2}{|l|}{$\begin{array}{l}\text { Geographic } \\
\text { Coordinates }\end{array}$} & \multicolumn{2}{l|}{$\begin{array}{l}\text { Magnetic } \\
\text { Coordinates }\end{array}$} & \multicolumn{2}{l|}{$\begin{array}{l}\text { C.P. Geographic } \\
\text { Coordinates }\end{array}$} \\
\cline { 2 - 7 } & $\begin{array}{l}\text { Glati } \\
\left({ }^{\mathbf{0}} \mathbf{N}\right)\end{array}$ & $\begin{array}{l}\text { Glongi } \\
\left({ }^{\mathbf{0}} \mathbf{E}\right)\end{array}$ & $\begin{array}{l}\text { Mlati } \\
\left({ }^{\mathbf{0}}\right)\end{array}$ & $\begin{array}{l}\text { Mlongi } \\
\left({ }^{\mathbf{0}} \mathbf{E}\right)\end{array}$ & $\begin{array}{l}\text { Glati } \\
\left({ }^{\mathbf{0}} \mathbf{N}\right)\end{array}$ & $\begin{array}{l}\text { Glongi } \\
\left({ }^{\mathbf{0}} \mathbf{E}\right)\end{array}$ \\
\hline $\begin{array}{l}\text { Tromso, } \\
\text { Norway (TR) }\end{array}$ & 69.9 & 19.2 & $\begin{array}{l}67.4 \\
-67.4\end{array}$ & $\begin{array}{l}116.5 \\
116.5\end{array}$ & -61.5 & 61.5 \\
\hline $\begin{array}{l}\text { Novosibirsk, } \\
\text { Russia (NS) }\end{array}$ & 54.6 & 83.2 & $\begin{array}{l}45.4 \\
-45.4\end{array}$ & $\begin{array}{l}159.9 \\
159.9\end{array}$ & -35.9 & 90.4 \\
\hline $\begin{array}{l}\text { Boulder, } \\
\text { USA (BC) }\end{array}$ & 40.0 & 254.7 & $\begin{array}{l}48.1 \\
-48.1\end{array}$ & $\begin{array}{l}321.2 \\
321.2\end{array}$ & -55.4 & 240.3 \\
\hline $\begin{array}{l}\text { Port Stanley, } \\
\text { UK (PS) }\end{array}$ & -51.6 & 302.1 & -41.9 & 12.0 & & \\
\hline $\begin{array}{l}\text { Mawson, } \\
\text { Australia (MW) }\end{array}$ & -67.6 & 62.9 & -73.2 & 111.4 & 72.1 & 298.2 \\
\hline
\end{tabular}


655 Fig.1. The UHRG VTEC (continuous line), compared with the performance of rapid and final combined IGS global VTEC maps (long-dashed and short-dashed lines), in terms of Standard Deviation (a) and relative RMS percentage (b) regarding to the daily mean reference VTEC value, taking as reference the actual JASON-2 VTEC measurements gathered over the oceans (days 119 to 292, 2012).

Fig.2 Example of the normalized relative error $\delta$ TEC for the daily set of GIM-TEC maps for April 25, 2011 (a - quiet day) and September 17, 2011 (b - storm) regarding source UHRG map. Here Z1PG is 1-day ahead forecast by IWAF system; EHRG - true hourly ESTEC map; JPLG - true 2-h JPL map; CODG - true 2-h CODE map; IGSG -true 2-h map averaged by UWM from other true IonoWG 2-h maps; U2PG - two days ahead forecast by UPC.

665 Fig.3. Comparison of the preliminary real-time (RT) UPC TEC maps urtg computed with a limited number of about 70 to 80 GPS receivers 17-24 January, 2012, with 1-day predicted TEC maps, z1pg (among the hourly $u h r g$, final upcg UPC maps and the final combined IGS one igsg) against JASON-2 direct VTEC measurements over the oceans. (a) Planetary Wp-index; (b) Root-mean square deviation, in percents; (c) Standard deviation; (d) Bias, in TECU. Fig. 4. Specification of ionospheric 'quiet' day, 'positive' storm day (dominant index $\mathrm{W}=3$ and 4) and 'negative' storm day (dominant index $\mathrm{W}=-3$ and -4 ) in terms of occurrence (in percent) of $\mathrm{W}$ index of the storm magnitudes calculated from UHRG maps (marked by $\mathrm{W}-\mathrm{u}$ and $\mathrm{W}+\mathrm{u}$ ) and JPLR maps (marked by $\mathrm{W}-\mathrm{j}$ and $\mathrm{W}+\mathrm{j}$ ) for three periods during 2012.

674 Fig.5. The global maps for the storm day on October 1, 2012, 1200 UT: (a) the source $u h r g$ TEC, and 675 the IWAF system products: (b) W-index map, (c) foF2 map, and (d) hmF2 map.

Fig.6. The world-wide distribution of more than 60 ionospheric observatories (circles) and their magnetic conjugate counterpart locations (triangles) used for online analysis at the Ionospheric

678 Weather site. Projection of the magnetic field line on the Earth's surface is shown by white lines for 679 five pairs of the conjugate locations used for the subsequent analysis (Table 5 and Figure 7). 
680 Fig.7. The hour-to-hour variation of foF 2 and hmF2 observed at five ionosonde stations (circles), the 681 IWAF products at the source stations (crosses) and at the magnetic conjugate counterpart locations 682 (dashed line) for the space weather storm on September 30, 1 and 2 October, 2012. The ring current 683 Dst index and the planetary Wp index are given in the lower sections.

684 Fig.8. The percentage daily peak occurrence of the W-index storm characteristics (total number of 685 cells of $\mathrm{W}= \pm 3$ and $\mathrm{W}= \pm 4$ on a map), their monthly average and the monthly mean solar radio flux, 686 F10.7, i.u., during 1999-2012.

687

688

689

690

691 